\title{
Elevation of Total Homocysteine in the Serum of Patients with Cobalamin or Folate Deficiency Detected by Capillary Gas Chromatography-Mass Spectrometry
}

\author{
Sally P. Stabler," Paul D. Marcell," Elaine R. Podell," Robert H. Allen,“ David G. Savage, and John Lindenbaum \\ *Divisions of Hematology and Oncology, Department of Medicine, and the Department of Biochemistry, Biophysics, and Genetics, \\ University of Colorado Health Sciences Center, Denver, Colorado 80262; and ${ }^{\ddagger}$ Departments of Medicine, Harlem Hospital Center, \\ Columbia-Presbyterian Medical Center and College of Physicians \& Surgeons, Columbia University, New York, New York 10032
}

\begin{abstract}
To determine if levels of serum total homocysteine are elevated in patients with either cobalamin or folate deficiency, we utilized a new capillary gas chromatographic-mass spectrometric technique to measure total homocysteine in the serum of $\mathbf{7 8}$ patients with clinically confirmed cobalamin deficiency and 19 patients with clinically confirmed folate deficiency. Values ranged from 11 to $476 \mu \mathrm{mol} /$ liter in the cobalamin-deficient patients and 77 of the 78 patients had values above the normal range of 7-22 $\mu \mathrm{mol} /$ liter as determined for 50 normal blood donors. In the cobalamin-deficient patients, serum total homocysteine was positively correlated with serum folate, mean corpuscular volume, serum lactate dehydrogenase, serum methylmalonic acid, and the degree of neurologic involvement, and inversely correlated with platelets and hematocrit. In the folate-deficient patients, values for serum total homocysteine ranged from 17 to $185 \mu \mathrm{mol} /$ liter and 18 of the 19 patients had values above the normal range. Some patients with pernicious anemia who were intermittently treated with cyanocobalamin were found to have elevated serum levels of total homocysteine while they were free of hematologic and neurologic abnormalities. The measurement of serum total homocysteine will help define the incidence of cobalamin deficiency and folate deficiency in various patient populations.
\end{abstract}

\section{Introduction}

At present the diagnosis of cobalamin $\left(\mathrm{Cbl},{ }^{1}\right.$ vitamin B12) deficiency and folate deficiency are almost entirely dependent on the demonstration of low serum levels of the vitamins in patients with supportive clinical and laboratory findings. The limitations in using only the serum $\mathrm{Cbl}$ level to detect $\mathrm{Cbl}$ deficiency have been widely recognized (1-4). For example, the significance of the high incidence of low serum $\mathrm{Cbl}$ values in elderly subjects without hematologic abnormalities $(5,6)$,

Address correspondence to Dr. Stabler, Div. of Hematology, Campus Box B170, University of Colorado Health Sciences Center, 4200 E. 9th Ave., Denver, CO 80262.

Received for publication 20 March 1987 and in revised form 7 July 1987.

1. Abbreviations used in this paper: Cbl, cobalamin; CN-Cbl, cyanoCbl; Hct, hematocrit; LDH, lactate dehydrogenase; MCV, mean corpuscular volume.

J. Clin. Invest.

(c) The American Society for Clinical Investigation, Inc. 0021-9738/88/02/0466/09 \$2.00

Volume 81, February 1988, 466-474 and in patients who have various neuropsychiatric abnormalities $(7,8)$, is not known. Other tests $(9)$, such as the deoxyuridine suppression test, have not been widely used to assess patients for $\mathrm{Cbl}$ deficiency.

The diagnosis of folate deficiency can also be problematic for several reasons. For instance, after acute dietary deprivation, serum folate levels may be decreased, although tissue folate levels are adequate (10). In the setting of chronic alcoholism, the laboratory features of megaloblastic anemia due to folate deficiency may be confused by concurrent illness. Serum and red blood cell folate may be normal in patients with alcoholism and megaloblastic anemia (11). Finally, because many of the clinical and laboratory features of $\mathrm{Cbl}$ and folate deficiency are similar, it is often difficult to distinguish between them (12), and the administration of folic acid alone to a patient with $\mathrm{Cbl}$ deficiency is dangerous (13). Therefore, as in Cbl deficiency syndromes, additional diagnostic tests for folate deficiency would be useful.

In both $\mathrm{Cbl}$ and folate deficiency, it is likely that there is reduced activity of the Cbl-dependent enzyme, methionine synthetase (tetrahydropteroylglutamate methyltransferase), which simultaneously methylates homocysteine to methionine while demethylating $\mathrm{N}^{5}$-methyltetrahydrofolate to tetrahydrofolate, as shown in Fig. 1. The reduced folates formed from this reaction are necessary for thymidine synthesis and ultimately DNA synthesis, and the methionine formed participates in the methylation of many compounds (14). If methionine synthetase activity is decreased by a deficiency of $\mathrm{Cbl}$ or folate, serum homocysteine levels might increase and methionine levels might decrease, although regulation of other enzymes in the pathway shown in Fig. 1 might maintain levels of one or both of these amino acids within normal limits. A few (15-20) but not all (21-24) children with severe Cbl deficiency have been reported to have increased levels of homocystine in their urine and plasma, along with decreased levels of plasma methionine. An early study (25) reported that plasma methionine levels were low in adults with $\mathrm{Cbl}$ deficiency. In addition, excretion of large amounts of homocystine in the urine has been reported in patients with various inherited defects affecting the activity of methionine synthetase such as the inability to form methylcobalamin (Cbl C and Cbl D mutants) $(26,27)$, and an inability to form $\mathrm{N}^{5}$-methyltetrahydrofolate due to 5,10-methylenetetrahydrofolate reductase deficiency $(28,29)$. However, homocystinuria was not present in patients with transcobalamin II deficiency (30), a patient with a lysosomal block in $\mathrm{Cbl}$ transport (31), or in a patient with congenital folate malabsorption (32), all of whom had hematologic abnormalities that would be associated with a decrease in methionine synthetase activity.

We have developed a new capillary gas chromatographic- 


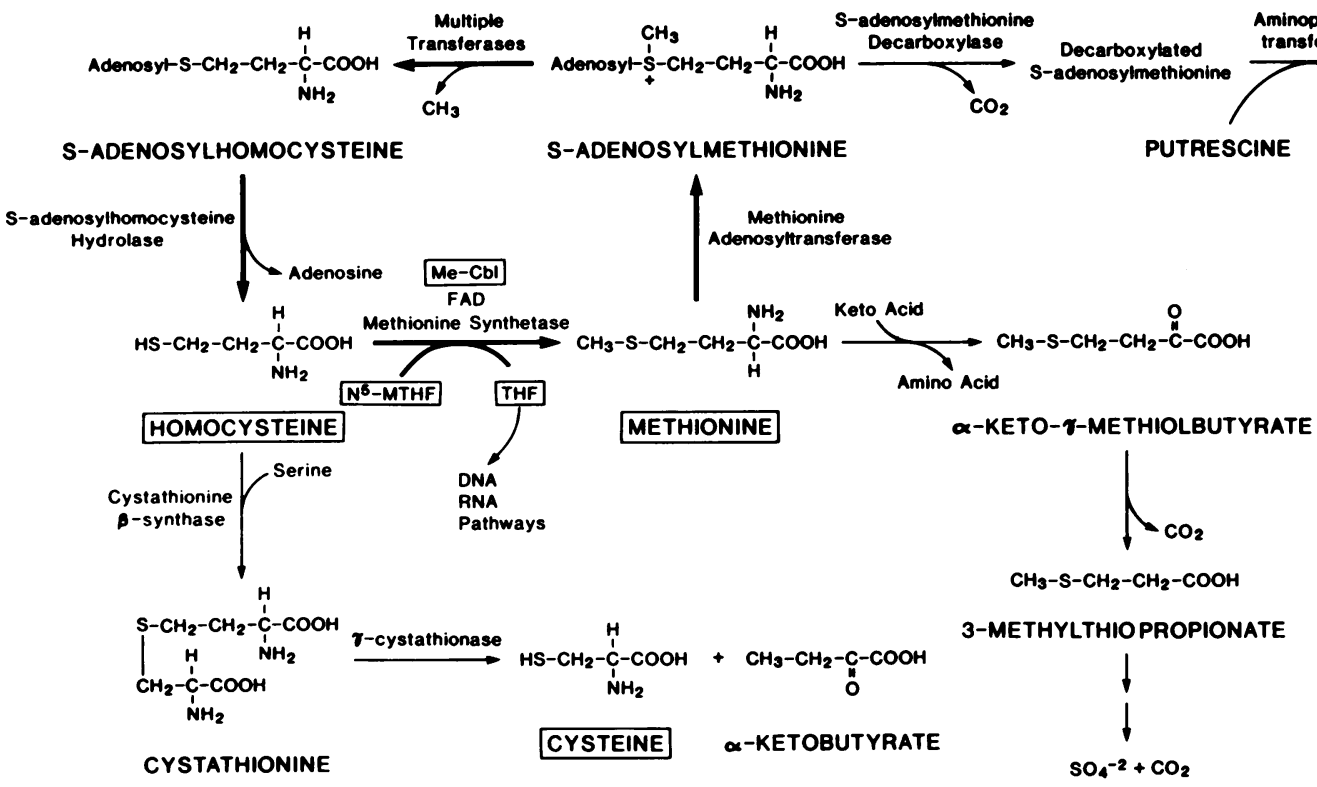

Figure 1. Various pathways involved in the metabolism of methionine including the methylcobalamin-dependent methylation of homocysteine to form methionine by the enzyme, methionine synthetase.

mass spectrometric assay for serum methylmalonic acid and have shown that 69 out of 73 patients with clinically confirmed $\mathrm{Cbl}$ deficiency have elevated values (33). We have recently developed similar assays (24) for the quantitation of total homocysteine, methionine, and total cysteine in serum and now report on the measurement of these amino acids in a large number of patients with clinically confirmed deficiencies of $\mathrm{Cbl}$ and folate.

\section{Methods}

Assay of total homocysteine, ${ }^{2}$ methionine, and total cysteine. ${ }^{2}$ Serum total homocysteine, methionine, and total cysteine were assayed using capillary gas chromatography-mass spectrometry as previously described in detail (34). Briefly, $50 \mu \mathrm{l}$ of $\mathrm{H}_{2} \mathrm{O}$ containing $5 \mathrm{nmol}$ of D, L- $\left[3,3,3^{\prime}, 3^{\prime} 4,4,4^{\prime} 4^{\prime}-{ }^{2} \mathrm{H}_{8}\right.$ ] homocystine (98.4\%), $15 \mathrm{nmol}$ of L-[methyl$\left.{ }^{2} \mathrm{H}_{3}\right]$ methionine $(98 \%)$, and $25 \mathrm{nmol}$ of $\mathrm{D}, \mathrm{L}-\left[3,3,3^{\prime}, 3^{\prime}-{ }^{2} \mathrm{H}_{4}\right]$ cystine ( $98 \%$ ), is added to $100 \mu \mathrm{l}$ of human serum. The sample is then heated with 2-mercaptoethanol in order to reduce and release endogenous homocysteine and cysteine from proteins and other disulfides and to equilibrate them with their stable isotope internal standards, which are also reduced during this procedure. Protein is then precipitated with sulfosalicylic acid and the supernatant is partially purified by sequential cation exchange and anion exchange chromatography. The $t$-butyldimethylsilyl derivatives of the amino acids are formed with $\mathrm{N}$ methyl-( $t$-butyldimethylsilyl)trifluoroacetamide, followed by their extraction into hexane and volume reduction using a stream of nitrogen.

2. The term "total homocysteine" as applied to biologic samples such as serum and urine refers to the sum of homocysteine and the homocysteine that is linked via disulfide bond formation in a variety of compounds that include homocystine (homocysteine-homocysteine disulfide), homocysteine-cysteine mixed disulfide, proteins via their cysteine moieties, and peptides such as glutathione via their cysteine moieties. The term "total cysteine" is used in the same way and refers to the sum of cysteine and the cysteine linked via disulfide bond formation in compounds such as cystine (cysteine-cysteine disulfide), homocysteine-cysteine mixed disulfide, and proteins and peptides via their cysteine moieties.
The samples are analyzed on a Durabond DB-1 fused silica capillary column ( $30 \mathrm{~m} \times 0.25 \mathrm{~mm}$ i.d., $0.25 \mu \mathrm{m}$ film thickness) from $\mathrm{J} \& \mathrm{~W}$ Scientific, Inc. (Rancho Cordova, CA) and a Hewlett-Packard Co. (Palo Alto, CA) 5992B gas chromatograph-mass spectrometer equipped with a falling needle injector. Quantitation is based on the

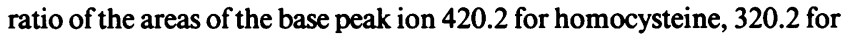
methionine, and 406.2 for cysteine, each of which elutes at a different time, to the areas of the base peak ions of $424.2,323.2$, and 408.2 for the derivatives of their respective stable isotope internal standards. Total homocysteine, methionine, and total cysteine are very stable in collected serum since no change or trend in values for these amino acids was noted in a sample of pooled normal human serum that was frozen, thawed, and assayed $>30$ times over a 12-mo period.

Values of serum total homocysteine obtained with blood samples that were drawn and immediately centrifuged at $4^{\circ} \mathrm{C}$ were the same ( $<10 \%$ difference) as those obtained with portions of the same blood samples that were incubated at room temperature for $1 \mathrm{~h}$ before centrifugation, but increased by $\sim 35$ and $75 \%$ when the incubation was prolonged for 4 and $24 \mathrm{~h}$, respectively, before centrifugation. Values for serum methionine were unchanged at $1 \mathrm{~h}$ and increased by 10 and $25 \%$ at 4 and $24 \mathrm{~h}$, respectively. Values for serum total cysteine were unchanged over the 24-h incubation period. Values for urine total homocysteine, total cysteine, and total methionine were unchanged when urine samples were incubated at room temperature for 0-24 h. Serum samples and the internal standards of homocysteine, methionine, and cysteine were stable for $>1 \mathrm{yr}$, based on their gas chromatographic-mass spectrometric behavior, when stored at $-20^{\circ} \mathrm{C}$ in between numerous freezings and thawings over this time period.

Subjects and patients. Serum samples from 50 normal blood donors, 25 males and 25 females, ranging in age from 18 to 65 yr were obtained as described previously (35). Patient samples were selected by Dr. Lindenbaum from an extensive serum collection that has been assembled over the past $15 \mathrm{yr}$. Both the normal and the patient samples were allowed to clot for $\sim 1-4 \mathrm{~h}$ at room temperature before the serum was removed and stored at $-20^{\circ} \mathrm{C}$. Thus, postcollection increases for total homocysteine and methionine should have been modest and similar in both the normal and patient groups (see above). The diagnosis of $\mathrm{Cbl}$ deficiency was based on low serum $\mathrm{Cbl}$ levels, megaloblastic bone marrow morphology, appropriate hematologic or neurologic abnormalities, and a significant response to treatment with parenteral $\mathrm{Cbl}$. The diagnosis of pernicious anemia was based on an abnormal 
Schilling test that corrected with exogenous intrinsic factor and/or the presence of anti-intrinsic factor-blocking antibodies in the serum. The diagnosis of folate deficiency was based on low serum folate values, normal or elevated serum Cbl values, megaloblastic bone marrow morphology, appropriate hematologic abnormalities, and responses to folic acid therapy. In 17 of the patients there was a history of alcoholism and poor diet; one had history of poor diet alone, and one had tropical sprue. The samples in the Cbl-deficient infrequently treated group were from patients with pernicious anemia who were previously diagnosed as Cbl deficient as described above, but who received only intermittent treatment with parenteral $\mathrm{Cbl}$ at intervals of 6-9 mo due to poor compliance or as part of studies of $\mathrm{Cbl}$ requirements to be reported elsewhere. They had low, borderline, or normal levels for serum $\mathrm{Cbl}$, lacked hematologic and neurologic abnormalities, and were asymptomatic at the time the samples were collected. Serum Cbl levels were assayed using the Lactobacillus leichmannii method or a number of radiodilution assays utilizing purified intrinsic factor or gastric juice with $>95 \%$ of $\mathrm{Cbl}$ binding activity due to intrinsic factor. These assays were performed in Dr. Lindenbaum's laboratory where it has been found that very similar patient values and normal ranges are obtained with all of the various $\mathrm{Cbl}$ assays. Serum folate was assayed with the Lactobacillus casei method or by milk binder radiodilution assay. Most of the patients' samples were coded in a manner such that the categories to which they belonged and the number of patients in each category were not known by the personnel involved in the performance of the total homocysteine, methionine, and total cysteine assays, until after the results were reported to Dr. Lindenbaum. A large number of Dr. Lindenbaum's samples from patients without $\mathrm{Cbl}$ or folate deficiency have been assayed and found to have normal values for these amino acids, thus ruling out the possibility that elevated values might arise due to storage in the freezers used in Dr. Lindenbaum's laboratory.

Statistical methods. A number of factors were examined individually for possible relationships with serum total homocysteine, methionine, and total cysteine. For factors that were discreet, such as sex, race, and diagnosis, the Wilcoxon two-sample test was used to determine the significance of the relation. For assessing possible relationships with neurologic severity, groups 0,1 , and 2 (as defined in Table I) were combined and compared with combined groups 3 and 4 . Factors that were continuous, such as age or mean corpuscular volume (MCV), were examined using Spearman correlation coefficients.

\section{Results}

The values obtained for serum total homocysteine, methionine, and serum total cysteine for the normal subjects and patients in the various categories are shown in Fig. 2. In the Cbl-deficient group, 77 of the 78 patients had values for serum total homocysteine above the normal range of $7-22 \mu \mathrm{mol} / \mathrm{liter}$. The highest value was $476 \mu \mathrm{mol} / \mathrm{liter}$ and the median value was $113 \mu \mathrm{mol} /$ liter. In the folate-deficient group, 18 of the 19 patients had serum total homocysteine levels above the normal range. The highest value in this group was $185 \mu \mathrm{mol} / \mathrm{liter}$ and the median value was $67 \mu \mathrm{mol} / \mathrm{liter}$. In the Cbl-deficient infrequently treated group, 13 of the 18 patients had elevated values that ranged as high as $47 \mu \mathrm{mol} / \mathrm{liter}$ at a time when they did not have hematologic or neurologic abnormalities. Of the thirteen patients with elevated total homocysteine values, serum L. leichmannii $\mathrm{Cbl}$ concentrations were low (88-180 $\mathrm{pg} / \mathrm{ml}$ ) in nine, two others were assayed by radiodilution and were both low at $115 \mathrm{pg} / \mathrm{ml}$, and two were normal by the $L$. leichmannii method at 205 and $275 \mathrm{pg} / \mathrm{ml}$, respectively. Of the five patients with normal total homocysteine values, two had low $\mathrm{Cbl}$ values by radioassay and one by the $L$. leichmannii method.
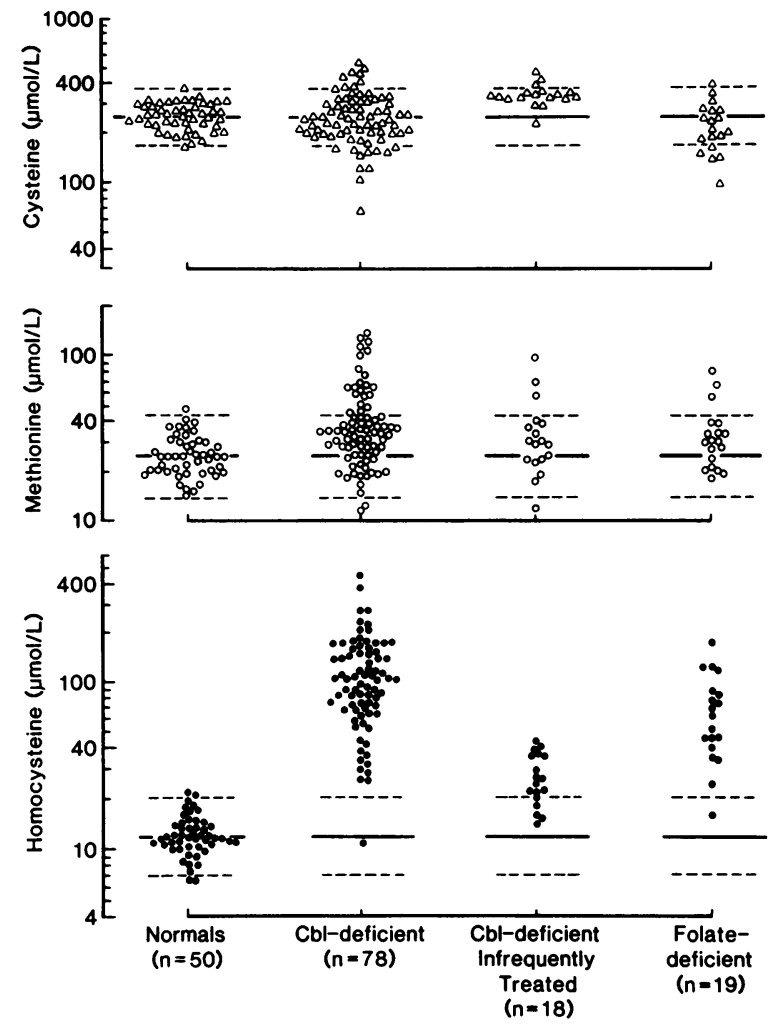

Figure 2. Levels of serum total homocysteine (bottom), serum methionine (middle), and serum total cysteine (top) in patients with clinically confirmed $\mathrm{Cbl}$ deficiency, folate deficiency, and Cbl-deficient infrequently treated patients who had no hematologic or neurologic abnormalities, using capillary gas chromatography-mass spectrometry. The normal range for total homocysteine is (7-22 $\mu \mathrm{mol} / \mathrm{liter})$, for methionine (14-44 $\mu \mathrm{mol} / \mathrm{liter}$ ), and for cysteine (173-378 $\mu \mathrm{mol} /$ liter). These ranges were calculated as the mean \pm 2 SD after log transformation to correct for skewness towards higher values.

To determine if the elevations of serum total homocysteine were due to $\mathrm{Cbl}$ or folate deficiency and not due to illness in general, we studied 25 consecutive patients ( 13 hospitalized, 12 outpatients; age, $25-86 \mathrm{yr}$ ) who had sera submitted for serum $\mathrm{Cbl}$ and serum folate assays and in whom the $\mathrm{Cbl}$ values were $>500 \mathrm{pg} / \mathrm{ml}$ (normal, $200-1,000 \mathrm{pg} / \mathrm{ml}$ ) and the folate values were $>5 \mathrm{ng} / \mathrm{ml}$ (normal, $3-20 \mathrm{ng} / \mathrm{ml}$ ). Of the $25 \mathrm{pa}-$ tients, 21 had values within the normal range of 7-22 $\mu \mathrm{mol} /$ liter (mean for the 21 patients, $13.7 \mu \mathrm{mol} / \mathrm{liter}$ ) and 1 had a very slightly elevated value of $22.5 \mu \mathrm{mol} / \mathrm{liter}$. Significantly elevated values of 32.6 and $27.4 \mu \mathrm{mol} / \mathrm{liter}$ were observed in two patients with chronic renal failure who had serum creatinine values of 5.6 and $13.3 \mathrm{mg} / \mathrm{dl}$, respectively. Various forms of homocysteine have been previously reported to be elevated in the plasma of patients with renal failure $(36,37)$. We are currently studying the incidence of elevated total homocysteine values in chronic renal failure. Preliminary results indicate that total homocysteine is elevated in many but not all such patients. A significantly elevated value of $34.4 \mu \mathrm{mol} /$ liter was also observed in one patient with $\mathrm{Cbl}$ deficiency since 1984, who had been intermittently treated with Cbl. The patient had not been treated for several months but had a serum $\mathrm{Cbl}$ of $>2,000 \mathrm{pg} / \mathrm{ml}$ because a Cbl injection was given $10-15$ $\min$ before the blood was drawn for the Cbl assay. Taken 
together, these results indicate that serum total homocysteine is not elevated in most ill patients.

In the Cbl-deficient group values for serum methionine were below the normal range of 14-44 $\mu \mathrm{mol} / \mathrm{liter}$ in only 2 of the 78 patients and above the normal range in 20 patients. Of the 19 folate-deficient patients, 3 had values above the normal range as did 3 of the $18 \mathrm{Cbl}$-deficient infrequently treated patients. None of the folate-deficient patients and only one of the Cbl-deficient infrequently treated patients had a value for serum methionine below the normal range.

Total serum cysteine was below the normal range in 11 of $78 \mathrm{Cbl}$-deficient patients, 4 of 19 folate-deficient patients, and none of the Cbl-deficient infrequently treated patients. It was above the normal range in 7 of $78 \mathrm{Cbl}$-deficient patients, 1 of the 19 folate-deficient patients, and 3 of the $18 \mathrm{Cbl}$-deficient infrequently treated patients.

The clinical data for the $78 \mathrm{Cbl}$-deficient patients in addition to their serum total homocysteine, methionine, total cysteine, and methylmalonic acid values are shown in Table I. They are arranged in descending order of their serum total homocysteine values. There was a significant positive correlation between serum total homocysteine and serum folate $(r$ $=0.27, P<0.05), \mathrm{MCV}(r=0.23, P<0.05)$, serum lactate dehydrogenase (LDH) $(r=0.34, P<0.01)$, and serum methylmalonic acid $(r=0.74, P<0.0001)$. There was a significant negative correlation between serum total homocysteine and platelets $(r=-0.26, P<0.05)$, and hematocrit (Hct) $(r$ $=-0.26, P<0.05)$. Patients with more severe neurologic abnormalities (groups 3 and 4) had higher serum total homocysteine levels ( $166 \pm 98$ mean $\pm \mathrm{SD}$, median $145 \mu \mathrm{mol} /$ liter) than those with no or less severe abnormalities (groups 0-2) (105 \pm 65 mean \pm SEM, median $89 \mu \mathrm{mol} /$ liter $)(P<0.01)$. Serum total homocysteine was not significantly correlated with serum $\mathrm{Cbl}(r=-0.20, P<0.08)$. There was no significant correlation between serum total homocysteine and any of the following: serum methionine, serum total cysteine, sex, race, etiology, presence of anti-intrinsic factor antibody, and presence of glossitis.

Serum methionine was not significantly correlated with any of the parameters mentioned above and significant differences were not observed between any of the various subgroups.

The hematologic data presented in Table I on the $77 \mathrm{Cbl}-$ deficient patients with elevated levels of total homocysteine, demonstrates wide variations in their degree of anemia, macrocytosis, and other abnormalities. For instance, only 32 $(42 \%)$ had a severe anemia (Hct $<25 \%)$, while $27(35 \%)$ had only a moderate degree of anemia (Hct, 25-34\% for females, $25-39 \%$ for males), and $18(23 \%)$ were not anemic at all. Only $45(58 \%)$ of the patients had a marked elevation in MCV (> $110 \mathrm{fl})$, while $23(30 \%)$ had only a moderate elevation of MCV (101-110 fl), and 9 (12\%) had a normal MCV. There was a wide range of serum $\mathrm{Cbl}$ levels in these patients also; only $47(61 \%)$ had markedly decreased levels to $<100 \mathrm{pg} / \mathrm{ml}$, while the other $30(39 \%)$ had levels between 100 and 200 $\mathrm{pg} / \mathrm{ml}$.

The clinical data on the 19 patients with folate deficiency along with their serum total homocysteine, methionine, total cysteine, and methylmalonic acid values are also shown in Table I. Because of the small number of patients tested, correlations between their clinical and laboratory abnormalities were not evaluated.

We have previously reported that serum methylmalonic acid is increased in $95 \%$ of patients with Cbl deficiency (33). As shown in Table 1,74 of the 78 Cbl-deficient patients had methylmalonic acid levels above the normal range of 19-76 $\mathrm{ng} / \mathrm{ml}$ (median, $1,240 \mathrm{ng} / \mathrm{ml}$, range, 78 to $2,300 \mathrm{ng} / \mathrm{ml}$ ). The one Cbl-deficient patient (No. 78) with a serum total homocysteine level within the normal range also had a normal serum methylmalonic acid. His diagnosis was tropical sprue. The other three patients with normal serum methylmalonic acid levels (Nos. 49, 61, and 73) all had elevated serum total homocysteine levels ranging from 34 to $92 \mu \mathrm{mol} / \mathrm{liter}$. Their diagnoses consisted of tropical sprue, postgastrectomy syndrome, and pernicious anemia.

As we have reported previously (33), most folate-deficient patients have normal levels of serum methylmalonic acid, although some have mild elevations. In the current study, as shown in Table I, 13 of the 19 folate-deficient patients had normal values for serum methylmalonic acid, and the other 6 had mild elevations (median for the 6 patients, $132 \mathrm{ng} / \mathrm{ml}$, range, 79 to $195 \mathrm{ng} / \mathrm{ml}$ ).

Fig. 3 shows the serum and urine homocysteine levels both before and after treatment in a patient with classic pernicious anemia and in another patient with alcoholism and nutritional folate deficiency. The Cbl-deficient patient had markedly elevated levels of total homocysteine both in serum and urine, which fell into the normal range within $3 \mathrm{~d}$ of treatment with parenteral cyano-Cbl $(\mathrm{CN}-\mathrm{Cbl})$. This same patient has been previously shown (33) to have a similar rapid fall in serum and urine methylmalonic acid in response to this course of $\mathrm{CN}-\mathrm{Cbl}$ treatment. The patient with folate deficiency had an elevated serum total homocysteine which over several days decreased to the upper border of the normal range after several doses of oral folic acid. The urine total homocysteine which was at the upper border of the normal range also fell markedly after treatment. This data suggests that serum and urine homocysteine levels correlate with each other in patients with $\mathrm{Cbl}$ or folate deficiency and could be used to monitor the response of treatment, although more patients would need to be evaluated before this could be concluded with certainty. Initial serum and urine methionine levels were normal in both patients and did not change significantly after $\mathrm{CN}-\mathrm{Cbl}$ or folate treatment (data not shown).

\section{Discussion}

Our studies demonstrate that serum total homocysteine levels are likely to be clinically useful, since they were above the normal range in 77 of $78 \mathrm{Cbl}$-deficient patients and 18 of 19 folate-deficient patients. The serum total homocysteine appears to be similar in sensitivity to the serum methylmalonic acid in the Cbl-deficient patients, since the latter was elevated in 74 of the same $78 \mathrm{Cbl}$-deficient patients. Using the serum total homocysteine level in combination with the serum methylmalonic acid level will often be helpful in distinguishing patients with $\mathrm{Cbl}$ deficiency from those with folate deficiency, since most patients with folate deficiency have normal levels of serum methylmalonic acid and the rest have only mild elevations.

Additional clinical studies using measurements of serum total homocysteine and serum methylmalonic acid in addition to measurements of serum $\mathrm{Cbl}$ and serum folate should make it possible to further define the clinical spectra of $\mathrm{Cbl}$ and folate deficiency, and to define the proper diagnostic approach 


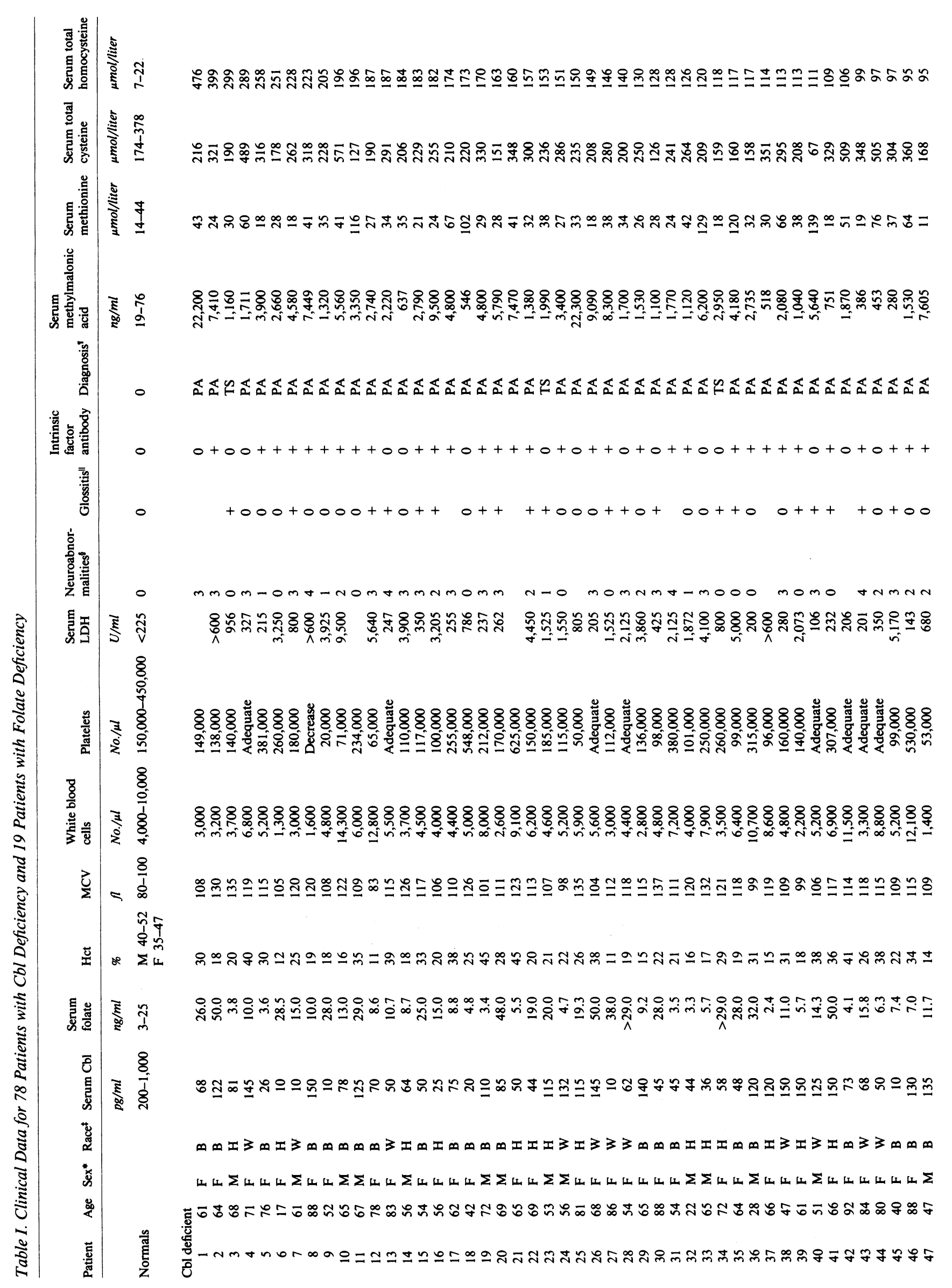




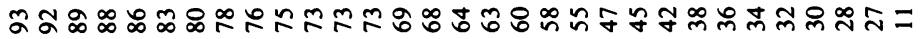

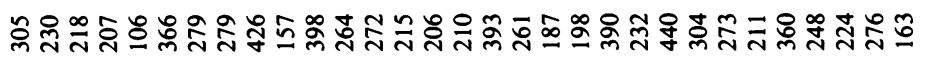

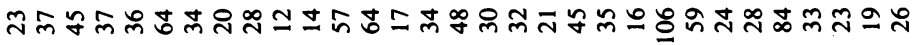

윰

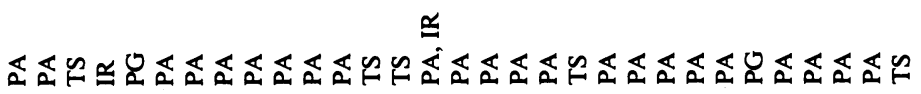

$0+0000 t+t+t+00 t+t 0+0 t+t+000 t+t 0$

$00000+t+0 t+0+000+t 00+00+00000$

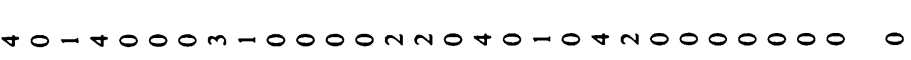

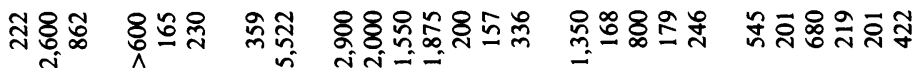

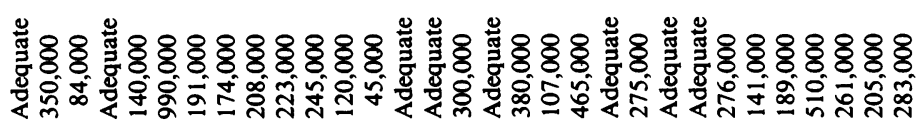

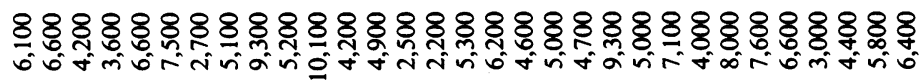

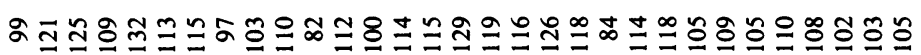

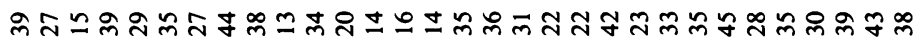
mi்

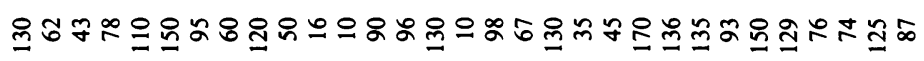
のロエ

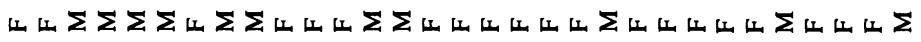

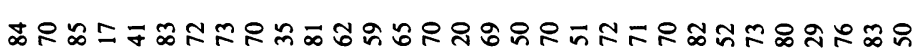

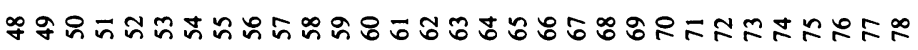

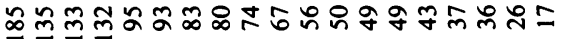

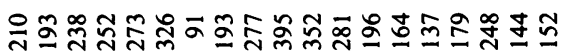

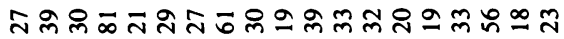

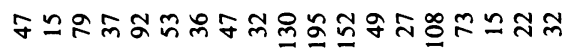

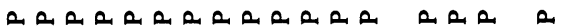

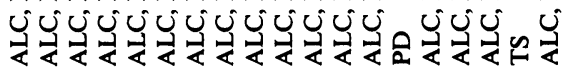

0000000000000000000

$+0+0+00000000$

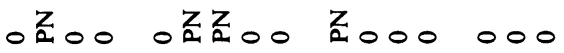

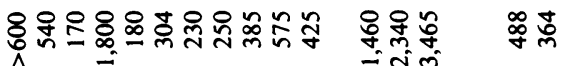
$88888888888888 \%$

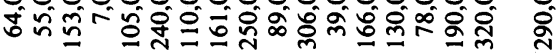

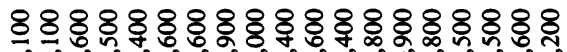
án

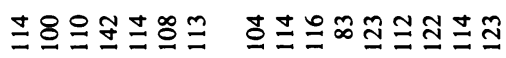

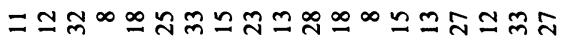

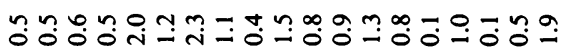

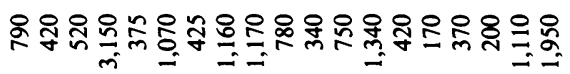

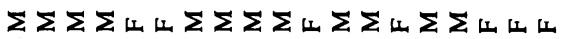

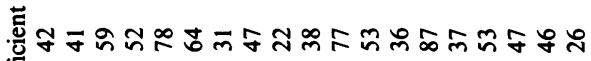
密

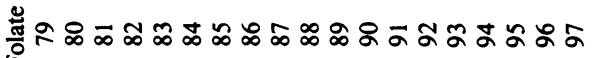




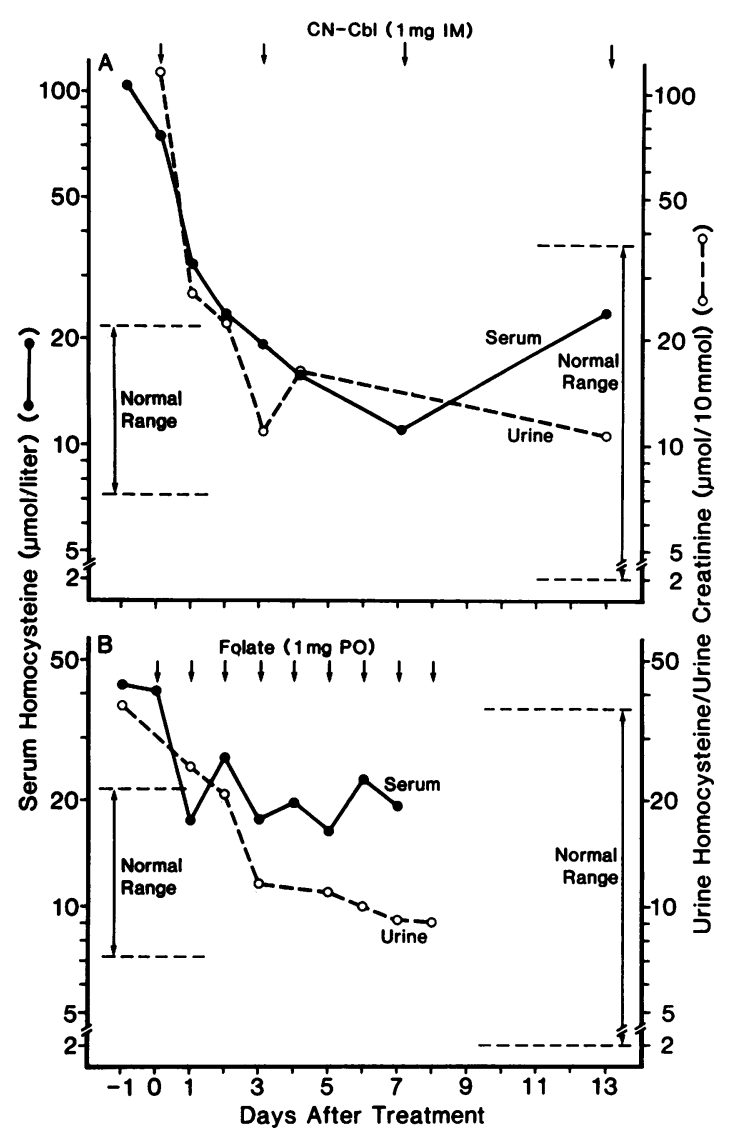

Figure 3. Levels of serum (๑) and urine (o) total homocysteine in $(A)$ a patient with pernicious anemia before and after treatment with $\mathrm{CN}-\mathrm{Cbl}$, and $(B)$ a patient with nutritional folate deficiency and alcoholism using capillary gas chromatography-mass spectrometry. $\mathrm{Pa}$ tient A was a 32-yr-old white male with pancytopenia, megaloblastic bone marrow findings, a serum $\mathrm{Cbl}$ value of $43 \mathrm{pg} / \mathrm{ml}$, serum antiintrinsic factor blocking antibodies, and an abnormal Schilling test that corrected with exogenous intrinsic factor. Patient B was a 52-yr-old black male with alcoholism and a poor diet who had severe anemia, megaloblastic bone marrow findings, a plasma folate value of 2.0 $\mathrm{ng} / \mathrm{ml}$, a red cell folate value of $41 \mathrm{ng} / \mathrm{ml}$, and a serum Cbl value of $690 \mathrm{pg} / \mathrm{ml}$. The $\mathrm{Cbl}$ was given by intramuscular (IM) injection and the folate was given by mouth. PO, per os.

to these patients. The importance of these studies is suggested by the fact that many of the Cbl-deficient patients in the current study had normal or only mildly abnormal values for various individual hematologic parameters such as Hct and MCV that are thought to be markedly or at least moderately abnormal in the vast majority of Cbl-deficient patients. Additional studies concerning the specificity of measurements of serum total homocysteine will also be of interest.

The serum total homocysteine and methylmalonic acid levels both have one advantage that is not shared by serum $\mathrm{Cbl}$ and serum folate levels in that one can treat a patient suspected of being Cbl-deficient with $\mathrm{Cbl}$ and then observe the effect on the serum total homocysteine and methylmalonic acid levels or treat a patient suspected of being folate-deficient with folate and then observe the effect on the serum total homocysteine level. If such treatment results in a decrease in the appropriate metabolite from the elevated to the normal range, this is strong presumptive evidence that the patient was $\mathrm{Cbl}$ deficient, or folate deficient, as was the case with the two patients described in detail in this report. This advantage is not shared by the serum $\mathrm{Cbl}$ and serum folate levels, since these values are always elevated or at least normal after treatment with $\mathrm{Cbl}$ or folate, respectively, regardless of whether a patient is Cbl- or folate-deficient or not.

That levels of serum total homocysteine are almost always elevated in deficiencies of $\mathrm{Cbl}$ and folate, whereas levels of serum methionine are almost never decreased in these conditions, indicates that the pathways shown in Fig. 1 are regulated to a considerable degree. The maintenance of methionine levels within a relatively narrow range appears reasonable, since methionine is an essential amino acid that plays an important role in protein synthesis, in various methylations, and in a large number of other metabolic reactions. The enzymatic reaction or reactions that represent the site or sites of regulation in $\mathrm{Cbl}$ deficiency and in folate deficiency are not known. Cystathione $\beta$-synthase (see Fig. 1) could play a role, since regulation of this enzyme is important in the maintenance of methionine homeostasis during changes in dietary methionine (38-40).

The fact that methionine levels are maintained in $\mathrm{Cbl}$ and folate deficiency at the expense of elevated levels of total homocysteine might be harmful, since elevations in homocysteine due to homozygosity or heterozygosity for cystathionine synthetase deficiency have been associated with an increase in vascular disease and thrombosis (41-43). That these problems have not been reported as being present in increased incidence in $\mathrm{Cbl}$ deficiency or in folate deficiency may be due to the shorter duration of $\mathrm{Cbl}$ and folate deficiencies or to possible differences in other regulatory factors that may exist in these conditions.

Our finding that serum total homocysteine is negatively correlated with platelet count and Hct and positively correlated with MCV and LDH in the Cbl-deficient patients supports the concept that a block in methionine synthetase activity occurs in $\mathrm{Cbl}$ deficiency and that this block is responsible for the megaloblastic anemia and other hematologic abnormalities that are seen in these patients (12), and which are indistinguishable from those seen in patients with folate deficiency. We have previously reported (33) and have found in this study that serum methylmalonic acid is not significantly correlated with Hct, MCV, or LDH in Cbl-deficient patients. This supports the concept that the second Cbl-dependent enzyme, L-methylmalonyl-CoA mutase, does not play a role in the megaloblastic anemia and other hematologic abnormalities seen in Cbl deficiency.

The cause of the neuropsychiatric abnormalities that are seen in $\mathrm{Cbl}$ deficiency but not in folate deficiency has long been of interest. Some investigators have favored a defect in L-methylmalonyl-CoA mutase as the cause and have suggested that the neuropsychiatric abnormalities are due to a buildup in propionyl-CoA and a resultant increase in odd number carbon fatty acids in peripheral nerves and the central nervous system (44-46). Other investigators have favored a defect in methionine synthetase as the cause and have suggested that the neuropsychiatric abnormalities are due to a lack of methionine and a resultant decrease in various methylation reactions in peripheral nerves and the central nervous system (47-49). Our studies are not helpful in distinguishing between these two possibilities since we have found that serum methylmalonic acid and serum total homocysteine are both strongly positively correlated with the presence and severity of 
neuropsychiatric abnormalities in patients with $\mathrm{Cbl}$ deficiency. Our finding that serum methionine is not decreased in patients with $\mathrm{Cbl}$ deficiency would appear to argue against a mechanism involving a lack of methionine as the cause of the neuropsychiatric abnormalities, but it should be emphasized that levels of methionine in serum may not reflect levels of methionine in peripheral nerves and the central nervous system. Measurements of methylmalonic acid, total homocysteine, and methionine in cerebral spinal fluid and various tissues would be of interest in this regard.

\section{Acknowledgments}

We thank Ms. Maria Ignacio for expert assistance in preparing the manuscript.

This work was supported by Department of Health and Human Services Research Grants DK21365 (to Dr. Allen) and DK37165 (to Dr. Stabler), awarded by the National Institutes of Diabetes and Digestive and Kidney Diseases.

\section{References}

1. Dawson, D. W. 1984. Diagnosis of vitamin $B_{12}$ deficiency. $B r$. Med. J. 289:938-939.

2. Lindenbaum, J. 1983. Status of laboratory testing in the diagnosis of megaloblastic anemia. Blood. 61:624-627.

3. Schilling, R. F., V. F. Fairbanks, R. Miller, K. Schmitt, and M. J. Smith. 1983. Improved vitamin $B_{12}$ assays: a report on two commercial kits. Clin. Chem. 29:582-583.

4. Beck, W. S. 1983. The assay of serum cobalamin by Lactobacillus leichmannii and the interpretation of serum cobalamin levels. Methods Hematol. 10:31-50.

5. Magnus, E. M., J. E. Bache-Wiig, T. R. Anderson, and E. Melbostad. 1982. Folate and vitamin $B_{12}$ (cobalamin) blood levels in elderly persons in geriatric homes. Scand. J. Haematol. 28:360-366.

6. Nexo, E. 1983. Variation with age of reference values for P-cobalamins. Scand. J. Haematol. 30:430-432.

7. Evans, D. L., G. A. Edelsohn, and R. N. Golden. 1983. Organic psychosis without anemia or spinal cord symptoms in patients with vitamin $\mathrm{B}_{12}$ deficiency. Am. J. Psychol. 140:218-221.

8. Cole, M. G., and J. F. Prchal. 1984. Low serum vitamin $B_{12}$ in Alzheimer-type dementia. Age Ageing. 13:101-105.

9. Metz, J., A. Kelly, V. C. Swett, S. Waxman, and V. Herbert. 1968. Deranged DNA synthesis by bone marrow from vitamin $B_{12}$-deficient humans. Br. J. Haematol. 14:575-592.

10. Herbert, V. 1962. Minimal daily adult folate requirement. Arch. Intern. Med. 110:649-652.

11. Savage, D., and J. Lindenbaum. 1986. Anemia in alcoholics. Medicine. 65:322-338.

12. Beck, W. S. 1983. Erythrocyte disorders: anemias related to disturbance of DNA synthesis (megaloblastic anemias). In Hematology. W. J. Williams, E. Beutler, A. J. Erslev, and M. A. Lichtman, editors. McGraw-Hill, Inc., New York. 434-465.

13. Vilter, C. F., R. W. Vilter, and T. P. Spies. 1947. The treatment of pernicious anemia and related anemias with synthetic folic acid. I. Observations on the maintenance of a normal hematologic status and the occurrence of combined system disease at the end of one year. $J$. Lab. Clin. Med. 32:262-273.

14. Mudd, S. H., and H. L. Levy. 1983. Disorders of transsulfuration. In The Metabolic Basis of Inherited Disease. J. B. Stanbury, J. B. Wyngaarden, D. S. Fredrickson, J. L. Goldstein, and M. S. Brown, editors. McGraw-Hill, Inc., New York. 522-559.

15. Fraden, J. O., B. Reibman, and D. Turkewitz. 1978. Vitamin $B_{12}$ deficiency in strict vegetarians. N. Engl. J. Med. 299:1319.

16. Higginbottom, M. C., L. Sweetman, and W. L. Nyker. 1978. A syndrome of methylmalonic aciduria, homocystinuria, megaloblastic anemia: neurologic abnormalities in a vitamin $B_{12}$-deficient breast-fed infant of a strict vegetarian. N. Engl. J. Med. 299:317-323.

17. Shipman, R. T., R. R. W. Townley, and D. M. Danks. 1969. Homocystinuria, Addisonian pernicious anemia, and partial deletion of a G chromosome. Lancet. ii:693-694.

18. Hollowell, J. G., Jr., W. K. Hall, M. F. Coryell, J. McPherson, Jr., and D. A. Hahn. 1969. Homocystinuria and organic aciduria in a patient with vitamin $B_{12}$ deficiency. Lancet. ii:1428.

19. Davis, J. R., Jr., J. Goldenring, and B. H. Lubin. 1981. Nutritional vitamin $\mathrm{B}_{12}$ deficiency in infants. Am. J. Dis. Child. 135:566567.

20. Hoey, H., J. C. Linnell, V. G. Oberholzer, and B. M. Laurance. 1982. Vitamin $B_{12}$ deficiency in a breastfed infant of a mother with pernicious anemia. J. Royal. Soc. Med. 75:656-658.

21. Graesbeck, R., R. Bordin, I. Kantero, and B. Kuhlbaeck. 1960. Selective vitamin $\mathrm{B}_{12}$ malabsorption and proteinuria in young people. Acta Medica Scandin. 167:289-296.

22. Lampkin, B. C., and A. M. Mauer. 1967. Congenital pernicious anemia with coexistent transitory intestinal malabsorption of vitamin B $_{12}$. Blood. 30:495-502.

23. Lambert, H. P., T. A. J. Prankerd, and I. M. Smellie. 1961. Pernicious anemia in childhood. Q. J. Med. 30:71-90.

24. Sievens, C. J. 1964. Megaloblastic anemia in a 3-year old child. Blood. 23:547. (Abstr.)

25. Parry, T. E. 1969. Serum valine and methionine levels in pernicious anaemia under treatment. Br. J. Haematol. 16:221-229.

26. Levy, H. L., S. H. Mudd, J. D. Schulman, P. M. Dreyfus, and R. H. Abeles. 1970. A derangement in $B_{12}$ metabolism associated with homocystinaemia, cystathionaemia, hypomethioninaemia, and methylmalonic aciduria. Am. J. Med. 48:390-397.

27. Goodman, S. I., P. G. Moe, K. B. Hammond, S. H. Mudd, and B. W. Uhlendorf. 1970. Homocystinuria with methylmalonic aciduria: two cases in a sibship. Biochem. Med. 4:500-515.

28. Mudd, S. H., B. W. Uhlendorf, J. M. Freeman, J. D. Finkelstein, and V. E. Shih. 1972. Homocystinuria associated with decreased methylenetetrahydrofolate reductase activity. Biochem. Biophys. Res. Commun. 46:905-912.

29. Freeman, J. M., J. D. Finkelstein, and S. H. Mudd. 1975. Folate-responsive homocystinuria and "schizophrenia" a defect in methylation due to deficient 5,10-methylenetetrahydrofolate reductase activity. N. Engl. J. Med. 292:491-496.

30. Scott, C. R., N. Hakami, C. C. Teng, and R. N. Sagerson. 1972. Hereditary transcobalamin II deficiency; the role of transcobalamin II in vitamin $B_{12}$-mediated reactions. J. Pediatr. 81:1106-1111.

31. Rosenblatt, D. S., R. Laframboise, J. Pichette, P. Langevin, B. A. Cooper, and T. Costa. 1986. New disorder of vitamin $B_{12}$ metabolism (cobalamin F) presenting as methylmalonic aciduria. Pediatrics. 78:51-54

32. Corbeel, L., G. Van der Berghe, J. Jaeken, J. von Tornout, and R. Eeckles. 1985. Congenital folate malabsorption. Eur. J. Ped. 143:284-290.

33. Stabler, S. P., P. D. Marcell, E. R. Podell, R. H. Allen, and J. Lindenbaum. 1986. Assay of methylmalonic acid in the serum of patients with cobalamin deficiency using capillary gas chromatography-mass spectrometry. J. Clin. Invest. 77:1606-1612.

34. Stabler, S. P., P. D. Marcell, E. R. Podell, and R. H. Allen. 1987. Quantitation of total homocysteine, total cysteine, and methionine in normal serum and urine using capillary gas chromatographymass spectrometry. Anal. Biochem. 162:185-196.

35. Marcell, P. D., S. P. Stabler, and R. H. Allen. 1985. Quantitation of methylmalonic acid and other dicarboxylic acids in normal serum and urine using capillary gas chromatography-mass spectrometry. Anal. Biochem. 150:58-66.

36. Wilcken, D. E. L., V. J. Gupta, and S. G. Reddy. 1980. Accumulation of sulphur-containing amino acids including cysteine-homocysteine in patients on maintenance haemodialysis. Clin. Sci. 58:427-430.

37. Kang, S. S., P. W. K. Wong, A. Bidani, and S. Milanez. 1983. 
Plasma protein-bound homocyst(e)ine in patients requiring chronic haemodialysis. Clin. Sci. 65:335-336.

38. Finkelstein, J. D., and S. H. Mudd. 1967. Transsulfuration in mammals. The methionine-sparing effect of cystine. J. Biol. Chem. 242:873-880.

39. Finkelstein, J. D., and J. J. Martin. 1984. Methionine metabolism in mammals. Distribution of homocysteine between competing pathways. J. Biol. Chem. 259:9508-9513.

40. Finkelstein, J. D., and J. J. Martin. 1986. Methionine metabolism in mammals. Adaptation to methionine excess. J. Biol. Chem. 261:1582-1587.

41. Wilcken, D. E. L., S. G. Reddy, and V. J. Gupta. 1983. Homocysteinemia, ischemic heart disease, and the carrier state for homocystinuria. Metab. Clin. Exp. 32:363-370.

42. Brattstrom, L. E., J. E. Hardebo, and B. L. Hultberg. 1984. Moderate homocysteinemia: a possible risk factor for arteriosclerotic cerebrovascular disease. Stroke. 15:1012-1016.

43. Boers, G. H. J., A. G. H. Smals, G. H. S. Antony, F. J. M. Trijbels, B. Fowler, J. A. J. M. Bakkeren, H. C. Schoonderwaldt, W. J. Kleijer, and P. W. C. Kloppenborg. 1985. Heterozygosity for homocystinuria in premature peripheral and cerebral occlusive arterial disease. N. Engl. J. Med. 313:709-715.
44. Frenkel, E. P. 1973. Abnormal fatty acid metabolism in peripheral nerves of patients with pernicious anemia. J. Clin. Invest. 52:1237-1245.

45. Kishimoto, Y., M. Williams, H. W. Moser, C. Hignite, and K. Biemann. 1973. Branched-chain and odd-numbered fatty acids and aldehydes in nervous system of a patient with deranged vitamin $B_{12-}$ metabolism. J. Lipid Res. 14:69-77.

46. Barley, F. W., G. H. Sato, and R. H. Abeles. 1972. An effect of vitamin $B_{12}$ deficiency in tissue culture. J. Biol. Chem. 247:1270-1276.

47. Scott, J. M., J. J. Dinn, P. Wilson, and P. G. Weir. 1981. Pathogenesis of subacute combined degeneration: a result of methyl group deficiency. Lancet. ii:334-337.

48. Van der Westhuyzen, J., S. V. van Tonder, J. E. Gibson, T. A. Kilroe-Smith, and J. Metz. 1985. Plasma amino acids and tissue methionine levels in fruit bats (Rousettus aegyptiacus) with nitrous oxide-induced vitamin $B_{12}$ deficiency. Br. J. Nutr. 53:657-662.

49. van der Westhuyzen, J., F. Fernandes-Costa, and J. Metz. 1982. Cobalamin inactivation by nitrous oxide produces severe neurological impairment in fruit bats: protection by methionine and aggravation by folates. Life Sci. 31:2001-2010. 